\title{
Characterization of the ftsH gene of Bacillus subtilis
}

\author{
Elena Lysenko, ${ }^{1}$ Teru Ogura ${ }^{2}$ and Simon M. Cutting ${ }^{1} \dagger$
}

Author for correspondence: Simon M. Cutting. Tel: +44 1784443760 . Fax: +44 1784434326. e-mail: s.cutting@rhbnc.ac.uk

\footnotetext{
1 Department of Microbiology, University of Pennsylvania School of Medicine, Philadelphia, PA 19104-6076, USA

2 Department of Molecular Cell Biology, Institute of Molecular Embryology and Genetics, Kumamoto University School of Medicine, Kumamoto 862, Japan
}

\begin{abstract}
Members of the AAA-protein family are found in both prokaryotes and eukaryotes. These ATPases are involved in a number of diverse activities ranging from protein secretion to cell cycle control. This paper reports the functional analysis of the Bacillus subtilis ftsH gene, which encodes a member of this protein family. In cells containing reduced levels of a truncated FtsH protein cell growth was impaired under certain nutritional conditions. In a hypersaline environment FtsH was required in increased amounts for the cells' recovery from osmotic stress. In the absence of FtsH the abundance of several of the major penicillin-binding proteins (PBP2A and 2B) in the cytoplasmic membrane was affected. Lastly, it has been established that FtsH is required for entry into the developmental life cycle.
\end{abstract}

Keywords: FtsH, cell cycle, B. subtilis, AAA-protein family, protease

\section{INTRODUCTION}

The ftsH gene of Bacillus subtilis has recently been genetically identified (Geisler \& Schumann, 1993) and has been sequenced in its entirety as part of the Bacillus genome sequencing project (Ogasawara et al., 1994). It is important since it encodes a prokaryotic member of the AAA-protein family of ATPases (ATPases associated with diverse cellular activities: Confalonieri \& Duguet, 1995; Kunau et al., 1993). Over 100 members of this protein family are known and are found not only in bacteria but also in eukaryotes, including Saccharomyces cerevisiae, Xenopus laevis and a number of mammals including humans. The AAA-proteins are involved in a multitude of varied activities, including protein secretion, protein assembly and proteolysis, peroxisome biogenesis, and cell cycle control. All members of this protein family have in common a large domain of about 200 amino acids containing an ATPbinding site, termed the AAA-module.

The first prokaryotic member of this family to be discovered was the FtsH protein of Escherichia coli (Ogura et al., 1991; Tomoyasu et al., 1993a), also referred to as hflB (Herman et al., 1993), and subsequently genes that could encode homologous proteins have been identified in Lactococcus lactis (Nilsson et al., 1994), B. subtilis (Ogasawara et al., 1994) and more recently from the genome sequencing projects for

†Present address: School of Biological Sciences, Royal Holloway University of London, Egham TW20 OEX, UK.
Haemophilus influenzae and Mycoplasma genitalium. The homology shared between the five prokaryotic FtsH proteins is substantial and extends beyond the AAAmodule. First, all contain two hydrophobic segments at the N-terminus. In the case of the E. coli and L. lactis proteins these segments have been shown to anchor $\mathrm{FtsH}$ to the phospholipid membrane by two transmembrane loops exposing the C-terminal AAA-module to the cytoplasm (Akiyama et al., 1994a; Nilsson et al., 1994; Tomoyasu et al., 1993b). Second, all contain a conserved C-terminal domain which is similar to the active site motif of zinc-metalloproteases. Interestingly, three membrane-bound mitochondrial proteins from $S$. cerevisiae (Yta10p, Yme1p/Yta11p and Yta12p) show remarkable similarity to the bacterial $\mathrm{FtsH}$ proteins, including the transmembrane domains and zinc metalloprotease active site (Tauer et al., 1994; Thorsness et al., 1993).

fts $H$ mutations are highly pleiotropic and affect cell growth, viability (Ogura et al., 1991) and a number of protein-membrane-associated events such as the secretion and assembly of polypeptides into membranes (Akiyama et al., 1994a, b; Tomoyasu et al., 1993a, b). The pleiotropy associated with $f t s H$ mutants has led to the suggestion that FtsH could function in some way as a chaperone, facilitating protein secretion and proteolysis. In B. subtilis and L. lactis fts $H$ mutants have been identified which are salt-sensitive, suggesting that FtsH may also be involved in the cell's response to stress (Deuerling et al., 1995; Geisler \& Schumann, 1993; Nilsson et al., 1994). Recently, the E. coli $\mathrm{FtsH}$ protein 
has been shown to be directly involved in the proteolytic degradation of both the $\lambda \mathrm{CII}$ protein and the heat-shock transcription factor $\sigma^{32}$ (Herman et al., 1995; Tomoyasu et al., 1995). FtsH has also been shown to be involved in the degradation of uncomplexed SecY, an essential component of the protein translocation machinery of $E$. coli, which may partially explain its pleiotropic effects on protein assembly and secretion (Kihara et al., 1995). The putative active-site motif for this proteolytic activity has been demonstrated to be essential for FtsH function (Qu et al., 1996).

In this work we have characterized the $f t s H$ gene of $B$. subtilis. We show that under certain conditions (e.g. in minimal medium) FtsH is required for cell growth and is in addition required for the cell's response to osmotic stress and spore formation.

\section{METHODS}

Bacterial strains, general methods and sporulation experiments. All strains used in this work were congenic derivatives of the wild-type $\left(\mathrm{Spo}^{+}\right)$, prototrophic, strain PY79. Routine cloning methods, PCRs, etc., were as described by Sambrook et al. (1989). B. subtilis methods (preparation of chromosomal DNA, transformations, etc.) were as described by Harwood \& Cutting (1990). Spectinomycin was used for growth and selection at a concentration of $100 \mu \mathrm{g} \mathrm{ml}^{-1}$. The 'exhaustion' method was used to induce sporulation (Nicholson \& Setlow, 1990). For measurement of $\beta$-galactosidase activity, samples $(1.0 \mathrm{ml})$ were removed, cells pelleted, and frozen at $-70^{\circ} \mathrm{C}$. The method of Miller (1972) was used to determine enzyme activity using the $\beta$-galactosidase substrate ONPG and specific activity was expressed as $\left(\Delta A_{420}\right.$ per min per $\mathrm{ml}$ culture per $\mathrm{OD}_{595}$ unit) $\times 1000$.

Construction of ftsH: : spc. Two oligonucleotide primers FTSF (5'-CGGGATCCGGATAAACCGAGCGGAAGA-3') and FTSR (5'-GCTCTAGAGGTGTTCCCCACATCGATA- $\left.{ }^{\prime}\right)$ that annealed to sequences (underlined) upstream (FTSF) and downstream (FTSR) of the $f t s H$ locus were used to amplify, by PCR, a $2.5 \mathrm{~kb}$ product containing the entire $f t s H$ gene (see Fig. 1). This DNA was digested with $S a c \mathrm{I}$ and EcoRI, which cut within the $f t s H$ ORF and ligated to a $1 \cdot 1 \mathrm{~kb} S a c l-E c o R I$ spectinomycin-resistance $\left(\mathrm{Sp}^{\mathrm{R}}\right)$ cassette (from pJR74 (LeDeaux \& Grossman, 1995). The ligated mixture was introduced directly into competent cells of $B$. subtilis strain PY79 with selection for $\mathrm{Sp}^{\mathrm{R}}$ at $30^{\circ} \mathrm{C}$. Approximately $100 \mathrm{Sp}^{\mathrm{R}}$ transformants were isolated by this procedure. Transformants should arise if the $S p^{\mathrm{R}}$ cassette had inserted by a marker replacement between the $S a c I$ and $E c o$ RI sites of the fts $H$ ORF to create a deletion $(\sim 1 \mathrm{~kb})$ and insertion mutation. A double crossover recombination would occur if the $5^{\prime}$ and $3^{\prime}$ ends of the $\mathrm{Sp}^{\mathrm{R}}$ cassette are flanked by the corresponding upstream and downstream fragments of the fts $\mathrm{H}$-amplified DNA. Several putative $f t s H$ mutants were isolated and checked as follows. First, linkage of $S p^{R}$ to a chloramphenicol resistance marker adjacent to the spolIE locus $(5 \mathrm{~kb}$ upstream of $f t s H)$

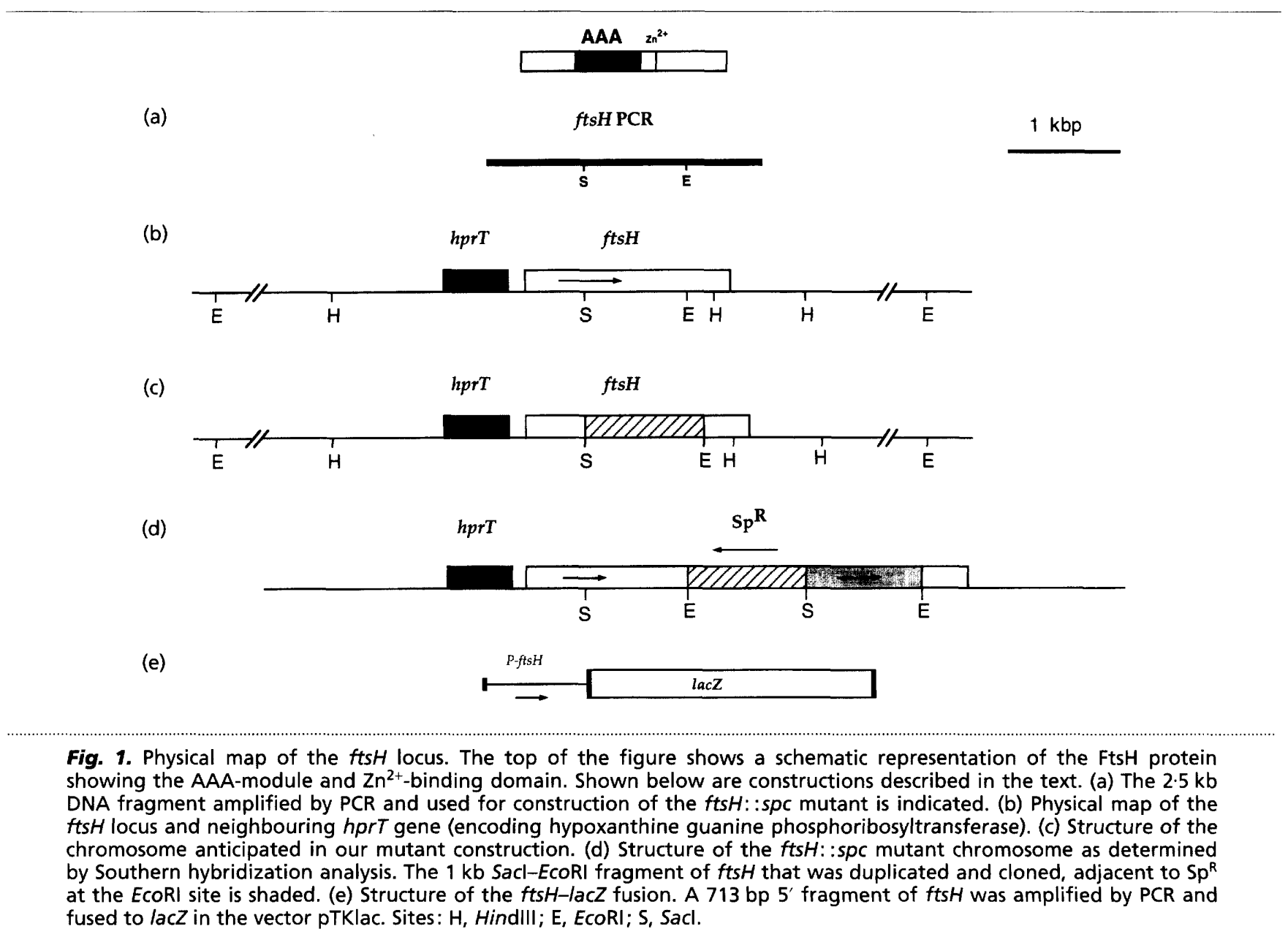


was confirmed by DNA-mediated transformation. Second, we used Southern hybridization analysis to examine the fts $H$ locus of the mutant chromosome. Analysis (not shown) of all clones revealed that insertion had not occurred between the SacI and EcoRI sites as predicted but rather at the EcoRI site alone. This insertion consisted of the $\mathrm{Sp}^{\mathrm{R}}$ cassette followed by a copy of the $1 \mathrm{~kb} S a c \mathrm{I}-E c o R I$ fts $H$ fragment fused to $S \mathrm{p}^{\mathrm{R}}$ (shown in Fig. 1). This construction separates the terminal 123 codons of the $f t s H$ ORF and leaves intact a functional ORF of 505 residues. It is unclear why our experimental approach failed to generate the anticipated $\mathrm{ftsH}$ null mutation; most probably, though, such an allele of fts $\mathrm{H}$ would be lethal, severely affecting cell growth, as is the case with $E$. coli. One mutant, EL273 ( $f t s H:: s p c$ ), was used for further characterization.

Immunological detection of FtsH. Membrane proteins $(50 \mu \mathrm{g})$ purified from vegetatively growing cells (see below) were fractionated on $12 \%$ SDS-polyacrylamide gels. Proteins were transferred to PVDF membrane (Millipore) and incubated with anti-E. coli FtsH serum $(1: 5000)$. FtsH was detected using the ECL Western blotting detection kit (Amersham).

Construction of ftsH-lacz. Two oligonucleotide primers, FTSF (see above) and OL61 (5'-CCCAAGCTTCCTCTGTATACTGCTTCGC-3') were used to amplify, by PCR, a 713 bp DNA product from the wild-type chromosome containing the $5^{\prime}$ region of $f s H$ (see Fig. 1). FTSF anneals to sequences within the $h p r T$ gene upstream of $f t s H$ and OL61 anneals to sequences within the $f t s H$ ORF. The amplified product was digested with BamHI and HindIII, which cut the $5^{\prime}$ and $3^{\prime}$ ends of the PCR product, and ligated to the vector p T.Klac cleaved with BamHI and HindIII. pTKlac contains a multiple cloning site upstream of the E. coli lacZ gene, facilitating the construction of transcriptional lacZ fusions (Kenney \& Moran, 1987). One plasmid was isolated in $E$. coli that contained the $f t s H 5^{\prime}$ region fused upstream and in the same direction as lacZ in pTKlac (see Fig. 1e). This plasmid, pEL8, was introduced into $B$. subtilis PY79 by DNA-mediated transformation with selection for $\mathrm{Cm}^{\mathrm{R}}$. $\mathrm{Cm}^{\mathrm{R}}$ transformants arose due to a single, Campbell-type, integration of pEL8 into the $f t s H$ locus since pTKlac cannot replicate autonomously in B. subtilis. Chromosomal DNA prepared from one $\mathrm{Cm}^{\mathrm{R}}$ transformant was used as a source of $\mathrm{ftsH}-\mathrm{lacZ}$ and introduced into subsequent strains by DNA-mediated transformation.

Purification of membrane proteins. Cultures $(250 \mathrm{ml})$ of cells growing exponentially $\left(\mathrm{OD}_{600} \sim 3.0\right)$ in $\mathrm{LB}$ medium were harvested and washed once with ice-cold buffer $(50 \mathrm{mM}$ Tris/ $\mathrm{HCl}, \mathrm{pH} 7 \cdot 5,1 \mathrm{mM} \mathrm{MgCl}, 1 \mathrm{M} \mathrm{KCl}, 0.1 \mathrm{mM}$ PMSF) and frozen rapidly at $-70^{\circ} \mathrm{C}$. To break the cells, the pellet was thawed and suspended in ice-cold buffer A $(100 \mathrm{mM}$ Tris/ $\mathrm{HCl}, \mathrm{pH} 8.0,1 \mathrm{mM} \mathrm{MgCl}, 1 \mathrm{mM} \beta$-mercaptoethanol, $0.1 \mathrm{mM}$ PMSF). Approximately $0.2 \mathrm{ml}$ glass beads was added and the mixture subjected to repeated cycles of sonication $(5 \times 30$ s) until more than $50 \%$ cell lysis had occurred. The broken cells were then diluted with $8 \mathrm{ml}$ buffer $\mathrm{A}$ and the mixture centrifuged $\left(8000 \mathrm{~g}, 10 \mathrm{~min}, 4^{\circ} \mathrm{C}\right)$. The supernatant was removed and centrifuged $\left(48000 \mathrm{~g}, 60 \mathrm{~min}, 4^{\circ} \mathrm{C}\right)$ and the pellet resuspended in $5 \mathrm{ml}$ buffer $\mathrm{B}(50 \mathrm{mM}$ Tris $/ \mathrm{HCl}, \mathrm{pH} 8 \cdot 0$, $1 \mathrm{mM} \beta$-mercaptoethanol, $0 \cdot 1 \mathrm{mM}$ PMSF) and centrifuged again $\left(48000 \mathrm{~g}, 60 \mathrm{~min}, 4^{\circ} \mathrm{C}\right)$. The 'membrane' pellet was suspended in $0.2 \mathrm{ml}$ buffer $\mathrm{B}$ and frozen in a dry-ice/ethanol bath for storage.

Detection of penicillin-binding proteins in vegetative membranes. A reaction mixture (final volume $50 \mu \mathrm{l}$ ) was prepared containing $50 \mu \mathrm{g}$ membrane proteins (see above), $50 \mathrm{mM}$ Tris $/ \mathrm{HCl}(\mathrm{pH} 8 \cdot 0), 1 \mathrm{mM} \mathrm{MgCl}_{2}$ and $40 \mu \mathrm{M}\left[{ }^{3} \mathrm{H}\right]$ benzyl- penicillin (Amersham) and incubated for $14 \mathrm{~min}$ at room temperature. The labelling reaction mixtures were then immediately mixed with gel loading dye and fractionated on SDS-polyacrylamide gels. Gels were treated with EnHance (NEN, DuPont), dried and exposed for $7 \mathrm{~d}$ at $-70{ }^{\circ} \mathrm{C}$.

\section{RESULTS}

\section{The ftsH: :spc mutant encodes a truncated protein, FtsH'}

We constructed an insertional fts $H:$ :spc mutant which disrupted translation of 123 residues of the C-terminus of $\mathrm{fts} H$ and left intact 505 codons of the ftsH ORF. We prepared and purified membrane proteins from vegetatively growing wild-type and mutant cells and size-fractionated polypeptides by SDS-PAGE. Using an anti-FtsH serum prepared to the $E$. coli FtsH protein we visualized FtsH protein in wild-type and ftsH: $s p c$ membranes by Western blotting (Fig. 2). In wild-type membrane extracts we observed a band migrating at approximately $70 \mathrm{kDa}$, absent in the $f t s H:: s p c$ mutant, and which corresponded to the molecular mass of the full-length FtsH polypeptide. The mutant, however, showed the presence of a band of approximately $57 \mathrm{kDa}$ (a)

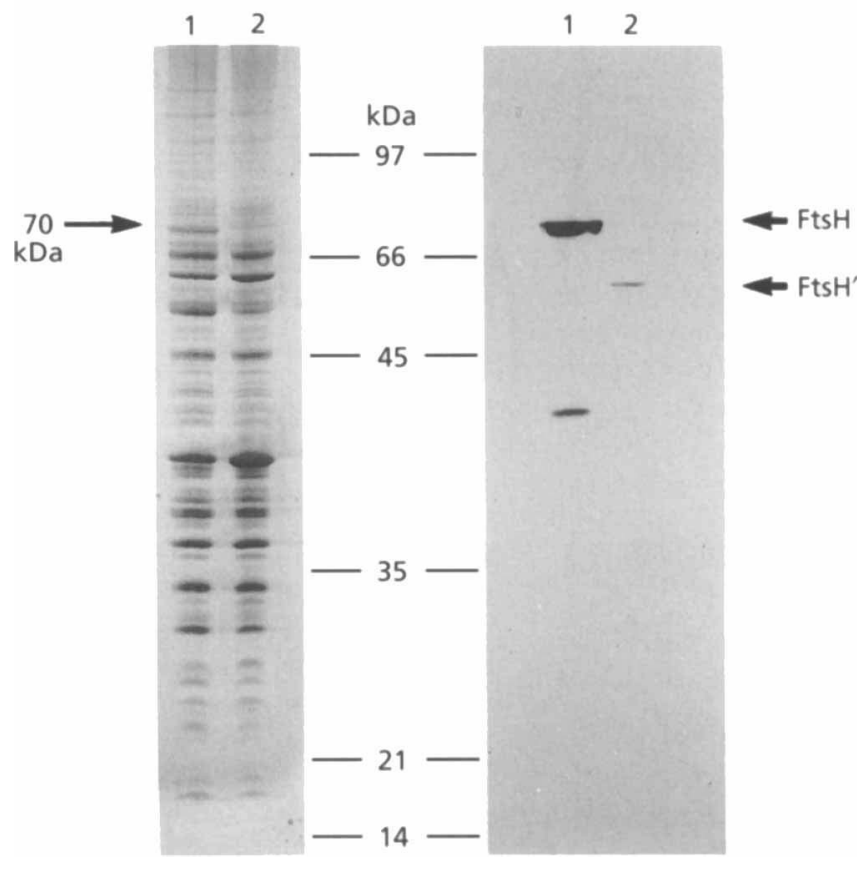

Fig. 2. Immunological detection of $\mathrm{FtsH}$ and $\mathrm{FtsH}^{\prime}$ in membrane fractions. Membrane proteins were purified from vegetatively growing cultures $\left(O D_{600} \sim 3.0\right.$ ) of a wild-type strain (PY79; lanes 1) and an ftsH::spc mutant (EL273; lanes 2). (a) Coomassieblue-stained proteins after fractionation on $12 \%$ SDSpolyacrylamide gels. The position of the $70 \mathrm{kDa} F t s H$ polypeptide is indicated. (b) Western blotting of the same gel fractionation with anti- $E$. coli FtsH serum. Indicated on the figure are the $70 \mathrm{kDa} F t s \mathrm{H}$ band present only in wild-type membranes and the $57 \mathrm{kDa}$ band found in $\mathrm{ftsH}: \mathrm{spc}$ membranes and which represents a truncated form of FtsH ( $\left.\mathrm{FtsH}^{\prime}\right)$. 

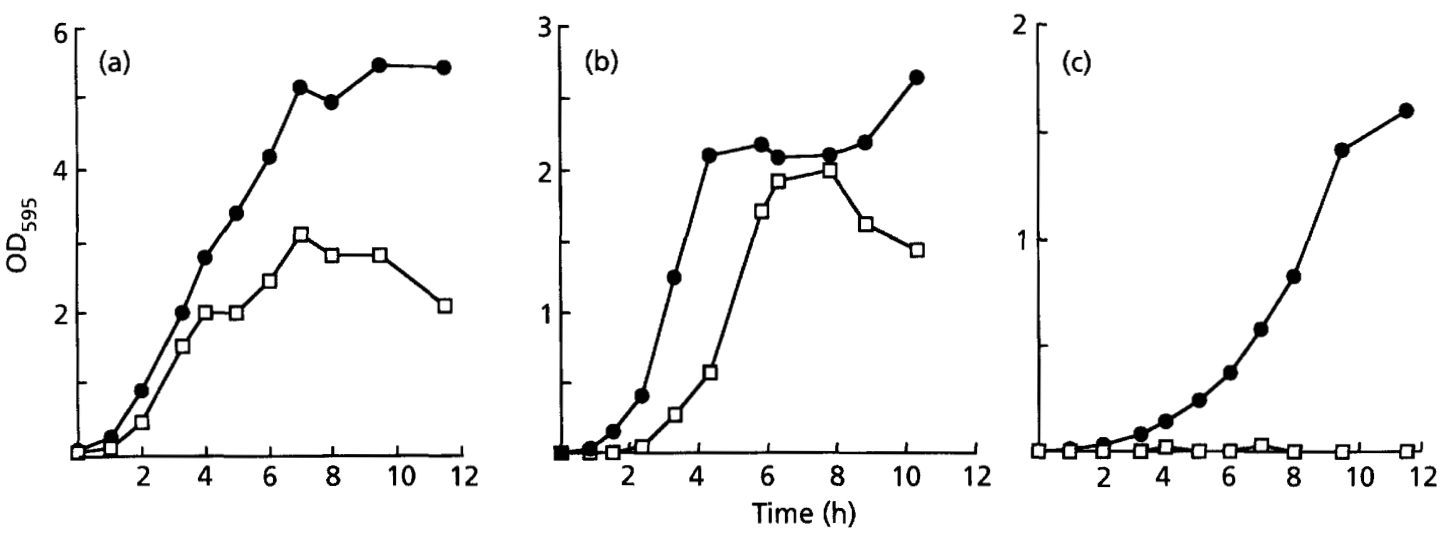

Fig. 3. Growth of ftsH: :spc. Wild-type (PY79, O) or $f t s H:: s p c(E L 273, \square)$ cells were grown at $37^{\circ} \mathrm{C}$ in LB medium (a), DSM sporulation medium (b), or glucose minimal medium (c).

which was absent in wild-type membranes. This band is most likely the $57 \mathrm{kDa}$ polypeptide synthesized from the truncated ORF present in the $f t s H:: s p c$ mutant, and we term this species $\mathrm{FtsH}^{\prime}$. However, the abundance of this polypeptide relative to wild-type $\mathrm{FtsH}$ was significantly reduced. Since FtsH' was present in the cytoplasmic membranes this polypeptide must presumably contain the $\mathrm{N}$-terminal transmembrane anchors present in $\mathrm{FtsH}$. It should also be noted that $\mathrm{FtsH}^{\prime}$ would contain all of the proposed functional domains required for activity of the E. coli FtsH protease. Thus, it is reasonable to assume that $\mathrm{FtsH}^{\prime}$ has at least partial activity and that the $f t s H:: s p c$ mutant can not be considered a null.

Our Western analysis also showed the presence of a $42 \mathrm{kDa}$ band present only in wild-type membranes. Incubation $(5-20 \mathrm{~min})$ of membrane extracts at $30^{\circ} \mathrm{C}$ and $37^{\circ} \mathrm{C}$ prior to SDS-PAGE analysis caused a marked increase in the intensity of this band and we infer that it is a degradation product of $\mathrm{FtsH}$. FtsH (and, to a lesser degree, $\mathrm{FtsH}^{\prime}$ ) appeared to exist as two distinct bands. On higher dilutions of antiserum we could not separate these bands although the upper, slower-migrating, band always produced a stronger signal (data not shown).

\section{FtsH is required for cell growth in minimal medium and for viability during stationary phase}

When grown on LB agar plates containing spectinomycin the ftsH: :spc mutant appeared to grow normally and was essentially indistinguishable from the congenic wild-type strain (PY79). Growth occurred at $30^{\circ} \mathrm{C}$, $37^{\circ} \mathrm{C}$ and $42^{\circ} \mathrm{C}$ and we observed no filamentation of cells during growth. However, ftsH: $s p c$ mutant cells were about twice the length of wild-type cells at equivalent stages of cell growth. Cells in LB medium showed a normal growth rate but failed to reach the same density as a wild-type culture at stationary phase (Fig. 3a), while in glucose minimal medium the mutant was unable to grow at all (Fig. 3c). In DSM sporulation medium (Fig. 3b), the mutant grew essentially at the same rate as the wild-type, but at stationary phase there was a marked decline in cell density as the culture

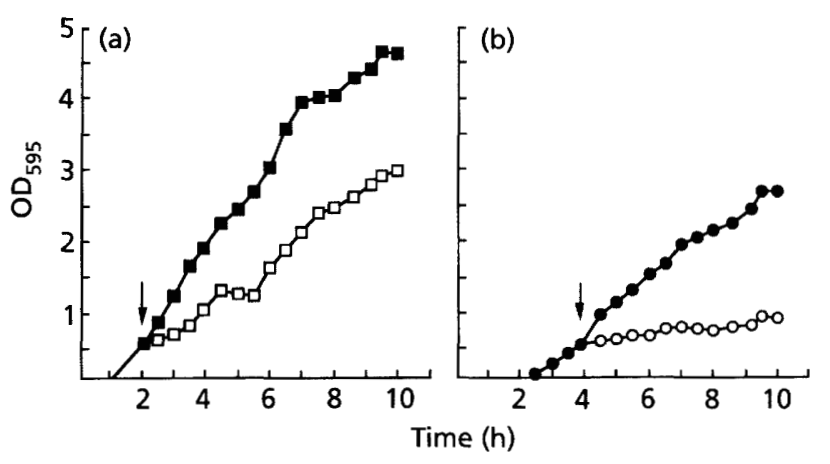

Fig. 4. Growth of $\mathrm{ftsH}: \mathrm{spc}$ in the presence or absence of salt. PY79 (wild-type) and EL273 (ftsH: :spc) were grown in LB at $37^{\circ} \mathrm{C}$ until the mid-exponential phase of growth. Cultures were divided and, to one portion, $\mathrm{NaCl}$ was added to a final concentration of $7 \%$ and incubation of both cultures continued. (a) PY79: $\square$, no salt; $\square$, plus salt. (b) EL273:, no salt; $O$, plus salt. Time of addition of salt is indicated by an arrow.

started to lyse. After $20 \mathrm{~h}$ incubation, up to $50 \%$ of the culture had lysed although continued lysis did not occur beyond this point. The increase in $\mathrm{OD}_{595}$ seen in wildtype cells beginning at hour 10 is due to the formation of phase-bright refractile spores which superficially increase the cell density measurements.

\section{FtsH is required under conditions of osmotic stress}

In other work a salt-sensitive mutation in B. subtilis fts $H$ has been described (Deuerling et al., 1995; Geisler \& Schumann, 1993) and a similar phenotype reported for a mutation in L. lactis ftsH (Nilsson et al., 1994). To determine whether our ftsH: :spc mutant exhibited a salt-sensitive phenotype we grew the mutant in LB medium and challenged exponentially growing cells with $7 \% \mathrm{NaCl}$. Under such conditions growth of the $f t s H:: s p c$ mutant was immediately arrested, whereas wild-type cultures experienced a lag followed by a resumption of normal growth (Fig. 4). On LB agar plates 


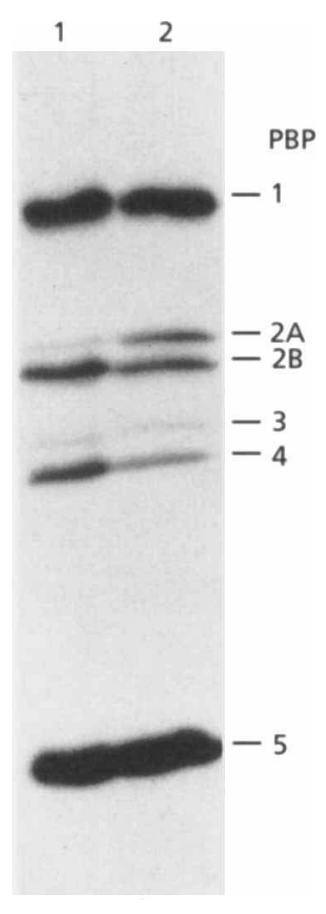

Fig. 5. Synthesis and assembly of penicillin-binding proteins during vegetative cell growth. Fluorograph of $\left[{ }^{3} \mathrm{H}\right]$ benzylpenicillin-labelled membrane proteins purified from vegetatively growing cells $\left(\mathrm{OD}_{600} \sim 3.0\right)$ of strain PY79 (wildtype; lane 1) and EL273 (ftsH::spc; lane 1). A $50 \mu \mathrm{g}$ sample of protein was labelled with $\left[{ }^{3} \mathrm{H}\right]$ benzylpenicillin and fractionated on a $10 \%$ SDS-polyacrylamide gel.

supplemented with $7 \% \mathrm{NaCl}$ the $f t s H:: s p c$ mutant was unable to form colonies at $30^{\circ} \mathrm{C}, 37^{\circ} \mathrm{C}$ or $42^{\circ} \mathrm{C}$.

\section{The ftsH: :spc mutant affects the amounts of active PBPs in the cytoplasmic membrane}

In E. coli $\mathrm{FtsH}$ is thought to be involved in the membrane assembly of PBP3 (Begg et al., 1992). The functional homologue of PBP3 in B. subtilis is PBP2B, which, like its $E$. coli counterpart, is believed to be essential for cell septum formation and thus cell division (Yanouri et al., 1993). We examined penicillin-binding proteins in vegetative membranes prepared from wildtype and mutant cells (Fig. 5). Following SDS-PAGE of ftsH::spc membrane proteins we could detect a reduction in the amounts of both PBP2B and PBP4. In contrast though, we observed a marked accumulation of PBP2A. We have repeated these experiments with more than one preparation of membrane proteins and although some of the differences were small (e.g. PBP2B) they were also reproducible.

\section{FtsH is essential for spore formation}

On DSM sporulation agar plates the $f t s H:: s p c$ mutant formed colonies that after $24 \mathrm{~h}$ incubation underwent extensive cell lysis. By phase-contrast microscopy we

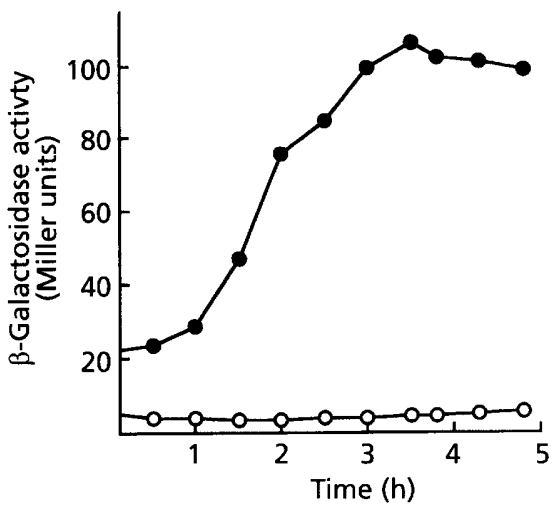

Fig. 6. FtsH is required for sporulation-specific gene expression. Wild-type (O, PY79) or ftsH: $s p c(O, E L 273)$ cells containing a spollE-lacZ transcriptional fusion were grown in DSM medium at $37^{\circ} \mathrm{C}$. spollE-directed $\beta$-galactosidase synthesis was determined at the indicated times following the initiation of sporulation $\left(t_{0}\right)$. Background levels of endogenous $\beta$ galactosidase activity present in PY79 cells containing no spollE-lacZ fusion have been subtracted. (The basal level of $\beta$ galactosidase activity present in wild-type cells at $t_{0}$, prior to induction of spolle expression, is due to a subpopulation of cells that have sporulated asynchronously and is often observed when using the exhaustion method for inducing sporulation.)

could observe the presence of a very low number of phase-bright refractile spores. It should be noted that under conditions of cell lysis visual examination of sporulation is misleading due to the enhancement of the relative amount of spores (which do not lyse). When sporulation was induced in DSM medium by the exhaustion method cells were unable to initiate spore formation at $30^{\circ} \mathrm{C}, 37^{\circ} \mathrm{C}$ or $42{ }^{\circ} \mathrm{C}$. Ten hours after the onset of sporulation less than $0.01 \%$ of the viable culture formed heat-resistant spores compared to almost $70 \%$ in wild-type cells.

To determine whether the cascade of sporulationspecific gene expression occurred in the ftsH: $s p c$ mutant we introduced $l a c Z$ transcriptional fusions to different sporulation genes into the $f t s H: s p c$ mutant and examined whether expression of these developmental genes was initiated in the mutant. With all genes tested (spoIIE, spoIID, spoIVF, sspE and gerE) we observed no developmental gene expression. In particular, expression of spoIIE-lacZ (Fig. 6) was prevented in the $f t s H$ : :spc mutant. spoIIE expression commences some $30 \mathrm{~min}$ after the initiation of sporulation, prior to formation of the two cell-types (Beall \& Lutkenhaus, 1991) and is controlled by the vegetative transcription factor $\sigma^{\mathrm{A}}$ and the sporulation-specific DNA-binding protein Spo0A.

\section{ftsH expression}

To examine expression of $f t s H$ we constructed an fts $\mathrm{H}-\mathrm{lac} \mathrm{Z}$ transcriptional fusion and measured $\mathrm{fts} H$ directed $\beta$-galactosidase synthesis in a $s p o^{+}$strain. In DSM medium, at the end of stationary phase, cells enter 


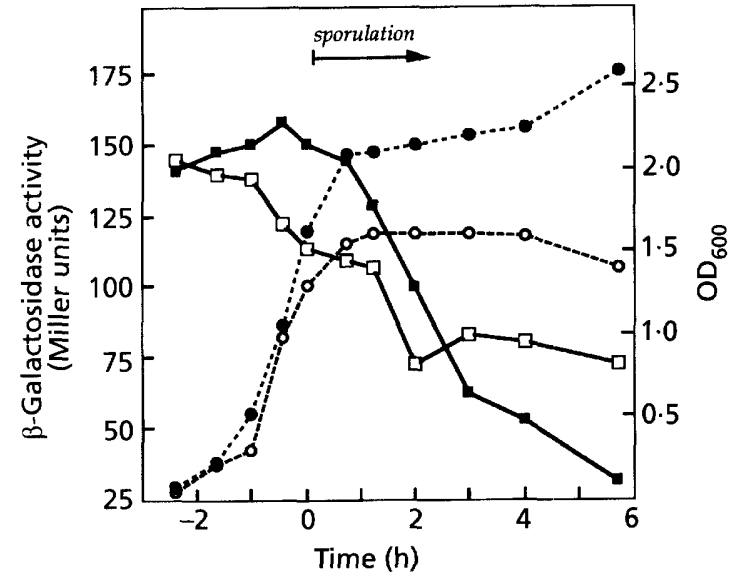

Fig. 7. Expression of the $\mathrm{fts} H$ gene. Cells containing an $\mathrm{ftsH}$-lac $\mathrm{Z}$ transcriptional fusion integrated at the $\mathrm{ftsH}$ locus were grown in DSM medium $\left(37^{\circ} \mathrm{C}\right)$ and $\mathrm{fts} H$-directed $\beta$ galactosidase synthesis was measured at the indicated times before and after the initiation of sporulation in a $\mathrm{spo}^{+}$wildtype strain (PY79, $\square$ ) and a spoOH $\Delta$ HindIII mutant (RL56, $\square$ ). Also shown are the cell densities of each culture $\left(O D_{600}\right)$ : PY79; O, RL56. Strains were isogenic and background levels of endogenous $\beta$-galactosidase activity present in PY79 cells containing no fts $\mathrm{H}-\mathrm{lacZ}$ fusion have been subtracted. Identical patterns of $\mathrm{fts} H$-directed $\beta$-galactosidase synthesis were obtained when sporulation was induced by the resuspension method (Nicholson \& Setlow, 1990).

the sporulation life cycle so both vegetative and developmental gene expression can be monitored. Fig. 7 shows that $\mathrm{ftsH}$ expression was maintained during vegetative growth but steadily declined as the cells entered the stationary phase of growth and continued to do so as the cells initiated spore formation.

Although $\mathrm{ftsH}-\mathrm{lacZ}$ expression declined as the cells initiated spore formation there were still significant levels of $\mathrm{fts} H$-directed $\beta$-galactosidase activity present 4-5 h after the commencement of spore development, suggesting that fts $\mathrm{H}$ expression might be developmentally controlled. The early stages of sporulationspecific gene expression are controlled by RNA polymerase associated with $\sigma^{\mathrm{H}}\left(\mathrm{E} \sigma^{\mathrm{H}}\right.$ : Errington, 1993). We introduced ftsH-lacZ into a mutant (RL56; spoOH $\Delta$ HindIII) unable to synthesize $\sigma^{\mathrm{H}}$ and measured ftsH expression. Our results (Fig. 7) showed that there was no substantial reduction in $f t s H$-directed $\beta$ galactosidase synthesis in the absence of $\mathrm{E} \sigma^{\mathrm{H}}$ and the pattern of $f t s H-l a c Z$ expression was essentially identical to that of $s \mathrm{po}^{+}$cells. In mutants unable to synthesize the sporulation-specific transcription factors $\sigma^{\mathrm{F}}, \sigma^{\mathrm{E}}, \sigma^{\mathrm{G}}$ or $\sigma^{\mathrm{K}}$, and in a strain unable to synthesize the stationaryphase transcription factor $\sigma^{\mathrm{B}}, \mathrm{ftsH}$ expression was similarly unaffected (not shown).

As shown above, the $f t s H$ mutant is unable to respond to conditions of osmotic stress and in order to recover from a hypersaline environment $\mathrm{FtsH}$ protein may be synthesized in increased amounts. To investigate this we measured $\mathrm{ftsH}-\mathrm{lac} \mathrm{Z}$ expression under conditions of salt

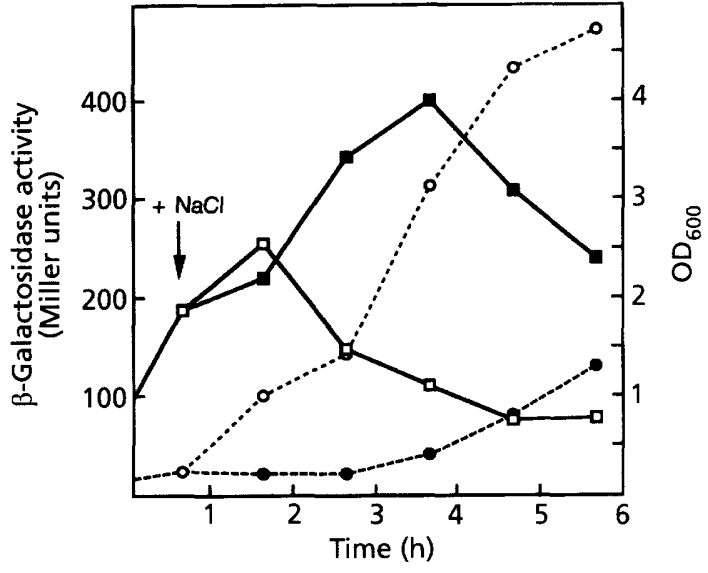

Fig. 8. Expression of $\mathrm{ftsH}$ under osmotic stress. Wild-type cells containing an $\mathrm{ftsH}-\mathrm{lacZ}$ transcriptional fusion integrated at the $\mathrm{fts} H$ locus were grown in LB medium $\left(37^{\circ} \mathrm{C}\right)$ and $\mathrm{fts} H$-directed $\beta$-galactosidase synthesis was measured at the indicated times before and after addition of $\mathrm{NaCl}$ (to a final concentration of $7 \%$ ). The arrow indicates the time of addition of $\mathrm{NaCl} . \square, \mathbf{\square}, \beta$ Galactosidase activity ( $\square$, no salt; $\square$, plus salt). 0,0 , Cell growth $\left(O D_{600}\right)(O$, no salt; $O$, plus salt).

stress (Fig. 8). Immediately following exposure to $\mathrm{NaCl}$ there was a twofold increase in $\mathrm{ftsH}$ expression. As cells adjusted to the high osmotic environment and finally resumed growth so ftsH-lac $\mathrm{Z}$ expression declined to its normal level.

\section{DISCUSSION}

The $f t s H:: s p c$ mutant constructed in this work encoded a truncated protein which contained the principal domains required for its proteolytic activity and membrane assembly. Most probably, this mutant protein retains some activity, yet our results show clearly that the protein accumulated in the membranes in reduced amounts. Modified activity or these reduced levels were, however, sufficient to produce significant cell growth defects, these being an inability to attain the normal cell density at stationary phase, failure to grow in minimal media, defective incorporation of some PBPs into the cytoplasmic membrane and failure to differentiate under conditions of nutrient depletion.

The relative abundance of three PBPs was altered in the $\mathrm{ftsH}$ mutant: there was an accumulation of PBP2A and a reduction in the amounts of PBP2B and PBP4. The function of PBP4 is least understood in $B$. subtilis but PBP2A has been implicated in the synthesis of the cell's side walls (Sowell \& Buchanan, 1983) and the presence of this protein in membranes declines rapidly as cells enter sporulation and when there is no requirement for cell elongation (thus PBP2A might be homologous to PBP2 of E. coli). In contrast, PBP2B is required for formation of the septum and indeed this protein is considered essential for cell growth (Yanouri et al., 1993). Furthermore PBP2B is also required for sporulation, where it is used for construction of the asym- 
metric spore septum, and synthesis of this polypeptide increases dramatically during development. PBP2B is homologous to $E$. coli $\mathrm{PBP} 3$ and both proteins play similar functional roles in septum formation and cell division (Yanouri et al., 1993). As in B. subtilis, membrane levels of E. coli PBP3 are substantially reduced in an ftsH mutant (Begg et al., 1992).

One explanation for the defective PBP assembly is that $\mathrm{FtsH}$ is involved in the membrane assembly of these proteins, perhaps in the role of a chaperone. Alternatively, $\mathrm{FtsH}$ could play a more direct role in the translocation of the PBPs into the plasma membrane. In E. coli SecY is an important component of the protein translocation machinery and normally exists in the membrane complexed with SecE. In the absence of FtsH, uncomplexed SecY accumulates to levels where it is deleterious to protein export, cell growth and viability (Kihara et al., 1995). Thus, FtsH can play a direct role in protein assembly and translocation by eliminating abnormally assembled SecY by proteolysis. In B. subtilis, FtsH could have an analogous role in controlling protein-membrane interactions such as the assembly of the PBPs.

In addition to causing a defect in cell growth the $\mathrm{fts} H$ mutation affected two other of the cell's responses to environmental stress, namely recovery from osmotic shock and spore formation. Under conditions of high osmolarity the $\mathrm{ftsH}$ mutant was unable to recover and maintain cell growth. This phenotype has been observed previously with other mutations in the $B$. subtilis and $L$. lactis FtsH proteins (Deuerling et al., 1995; Nilsson et al., 1994) and suggests that $\mathrm{FtsH}$ plays an important role in the cell's response to osmotic stress. Under such conditions we have shown that transcription of the $\mathrm{ftsH}$ gene is induced twofold and continues to be overexpressed until the cell has recovered from the hypersaline environment and resumed cell growth. Enhanced expression of $f t s H$ under stress is reminiscent of the prokaryotic heat-shock response, and a simple explanation for the increased levels of FtsH would be that it may be required for the degradation of a regulatory factor required for the cell's survival in a hypersaline environment, in a manner analogous to the $\mathrm{FtsH}$ mediated degradation of the heat-shock transcription factor, $\sigma^{32}$ (Herman et al., 1995; Tomoyasu et al., 1995). Intriguingly, $\mathrm{FtsH}$ is anchored to the membrane by two transmembrane domains which would expose a stretch of over 80 amino acids on the outer face of the cytoplasmic membrane beneath the peptidoglycan cell wall. Conceivably, this domain might be required as part of a sensory domain for responding to stress conditions. In other experiments (E. Lysenko \& S. Cutting, unpublished) we have found that in a $\operatorname{sig} B$ mutant unable to synthesize the transcription factor $\sigma^{\mathrm{B}}$, $f t s H$ was induced normally following exposure to salt. Thus, $\sigma^{\mathrm{B}}$ is not required for the salt-induced expression of $f t s H$.

We have also shown that the $\mathrm{ftsH}$ mutant is unable to enter the developmental life cycle under starvation conditions. Using an ftsH-lac Z fusion we have demon- strated that expression of $f t s H$ actually declines as cells differentiate, so the involvement of $\mathrm{FtsH}$ here must be different from that in the osmotic stress response. Interestingly, spollE was not expressed in the $f t s H$ mutant. spolle transcription is controlled by $\sigma^{A}$ and Spo0A. Spo0A is activated by an elaborate phosphorelay signal transduction pathway requiring a number of cellular inputs (cell cycle, nutritional and extracellular signalling: Burbulys et al., 1991; Ireton \& Grossman, 1994). Failure to elicit spollE-lacZ expression suggests that Spo0A may be inactive in the $\mathrm{fts} H$ mutant. Although only a hypothesis, this could explain the block in development under conditions of nutrient depletion.

In summary, our work shows that $\mathrm{FtsH}$ is most likely a general factor involved in cell growth, response to stress conditions and in spore formation. It should be noted that most of these events are related to membrane functions.

\section{ACKNOWLEDGEMENTS}

We thank Dr Dan Nilsson, Dr Wolfgang Schumann and Dr James Lear for their valuable advice and Dr Mikhail Shchepetov for his contribution. S.C. is the recipient of a Junior Faculty Research Award from the American Cancer Society (JFRA-514). This work was supported by NIH grant GM49206 and NSF grant no. IBN-9418291 to S. C. and grants from the Ministry of Education, Science, Sports and Culture of Japan to T.O.

\section{REFERENCES}

Akiyama, Y., Ogura, T. \& Ito, K. (1994a). Involvement of FtsH in protein assembly into and through the membrane. I. Mutations that reduce retention efficiency of a cytoplasmic reporter. $J$ Biol Chem 269, 5218-5224.

Akiyama, Y., Shirai, Y. \& Ito, K. (1994b). Involvement of FtsH in protein assembly into and through the membrane. II. Dominant mutations affecting FtsH functions. J Biol Chem 269, 5225-5229.

Beall, B. \& Lutkenhaus, J. (1991). FtsZ in Bacillus subtilis is required for vegetative septum and for asymmetric septation during sporulation. Genes Dev 5, 447-455.

Begg, K. I., Tomoyasu, T., Donachie, W. D., Khattar, M., Niki, H., Yamanaka, K., Hiraga, S. \& Ogura, T. (1992). Escherichia coli mutant $\mathrm{Y} 16$ is a double mutant carrying thermosensitive $f t s \mathrm{H}$ and ftsI mutations. J Bacteriol 174, 2416-2417.

Burbulys, D., Trach, K. A. \& Hoch, J. A. (1991). Initiation of sporulation in $B$. subtilis is controlled by a multicomponent phosphorelay. Cell 64, 545-552.

Confalonieri, F. \& Duguet, M. (1995). A 200-amino acid ATPase module in search of a basic function. BioEssays 17, 639-650.

Deuerling, E., Paeslack, B. \& Schumann, W. (1995). The $f t s H$ gene of Bacillus subtilis is transiently induced after osmotic and temperature upshift. J Bacteriol 177, 4105-4112.

Errington, J. (1993). Bacillus subtilis sporulation: regulation of gene expression and control of morphogenesis. Microbiol Rev 57, $1-33$.

Geisler, U. \& Schumann, W. (1993). Isolation of stress mutants of Bacillus subtilis by a novel genetic method. FEMS Microbiol Lett 108, 251-254.

Harwood, C. R. \& Cutting, S. M. (1990). Molecular Biological Methods for Bacillus. Chichester: Wiley. 
Herman, C., Ogura, T., Tomoyasu, T., Hiraga, S., Akiyama, Y., Ito, K., Thomas, R., D'Ari, R. \& Bouloc, P. (1993). Cell growth and $\lambda$ phage development controlled by the same essential Escherichia coli gene, ftsH/hflB. Proc Natl Acad Sci USA 90, 10861-10865.

Herman, C., Thevenet, D., D'Ari, R. \& Bouloc, P. (1995). Degadation of $\sigma^{32}$, the heat shock regulator in E. coli, is governed by HflB. Proc Natl Acad Sci USA 92, 3516-3520.

Ireton, K. \& Grossman, A. D. (1994). A developmental checkpoint couples the initiation of sporulation to DNA replication in Bacillus subtilis. EMBO J 13, 1566-1573.

Kenney, T. J. \& Moran, C. P. (1987). Organization and regulation of an operon that encodes a sporulation-essential sigma factor in Bacillus subtilis. J Bacteriol 169, 3329-3339.

Kihara, A., Akiyama, Y. \& Ito, K. (1995). FtsH is required for proteolytic elimination of uncomplexed forms of SecY, an essential protein translocase subunit. Proc Natl Acad Sci USA 92, 4532-4536.

Kunau, W. H., Beyer, A., Franken, T., Gotte, K., Marzioch, M., Saidowsky, J., Skaletz-Rorowski, A. \& Wiebel, F. F. (1993). Two complementary approaches to study peroxisome biogenesis in Saccharomyces cerevisiae: forward and reversed genetics. Biochimie 75, 209-224.

LeDeux, J. R. \& Grossman, A. D. (1995). Isolation and characterization of $k i n C$, a gene that encodes a sensor kinase homologous to the sporulation sensor kinases $\mathrm{KinA}$ and $\mathrm{KinB}$ in Bacillus subtilis. J Bacteriol 177, 166-175.

Miller, J. (1972). Assay of $\beta$-galactosidase. In Experiments in Molecular Genetics, pp. 352-355. Cold Spring Harbor, NY: Cold Spring Harbor Laboratory.

Nicholson, W. L. \& Setlow, P. (1990). Sporulation, germination and outgrowth. In Molecular Biological Methods for Bacillus, pp. 391-450. Edited by C. R. Harwood \& S. M. Cutting. Chichester: Wiley.

Nilsson, D., Lauridsen, A. A., Tomoyasu, T. \& Ogura, T. (1994). A Lactococcus lactis gene encodes a membrane protein with putative ATPase activity that is homologous to the essential Escherichia coliftsH gene product. Microbiology 140, 2601-2610.

Ogasawara, N., Nakai, S. \& Yoshikawa, H. (1994). Systematic sequencing of the 180 kilobase region of the Bacillus subtilis chromosome containing the replication origion. DNA Res 1, $1-14$.

Ogura, T., Tomoyasu, T., Yuki, T., Morimura, S., Begg, K. J., Donachie, W. D., Mori, H., Niki, H. \& Hiraga, S. (1991). Structure and function of the ftsH gene in Escherichia coli. Res Microbiol 142, 279-282.

Qu, J. N., Makino, S., Adachi, H., Koyama, Y., Akiyama, Y., Ito, K., Tomoyasu, T., Ogura, T. \& Matsuzawa, H. (1996). The tolZ gene of Escherichia coli is identified as the fts $H$ gene. J Bacteriol 178, 3457-3461.

Sambrook, J., Fritsch, E. F. \& Maniatis, T. (1989). Molecular Cloning: a Laboratory Manual, 2nd edn. Cold Spring Harbor, NY: Cold Spring Harbor Laboratory.

Sowell, M. O. \& Buchanan, C. E. (1983). Changes in the penicillinbinding proteins during sporulation of Bacillus subtilis. I Bacteriol 153, 1331-1337.

Tauer, R., Mannhaupt, G., Schnall, R., Pajic, A., Langer, T. \& Feldmann, H. (1994). Yta10p, a member of a novel ATPase family in yeast, is essential for mitochondrial function. FEBS Lett 353, 197-200.

Thorsness, P. E., White, K. H. \& Fox, T. D. (1993). Inactivation of YME1, a member of the ftsH-SEC18-PAS1-CDC48 family of putative ATPase-encoding genes, causes increased escape of DNA from mitochondria in Saccharomyces cerevisiae. Mol Cell Biol 13, $5418-5426$.

Tomoyasu, T., Gamer, J., Bukau, B., Kanemori, M., Mori, H., Rutman, A., Oppenheim, A. B., Yura, T., Yamanaka, K., Niki, H., Hiraga, S. \& Ogura, T. (1995). Escherichia coli FtsH is a membranebound, ATP-dependent protease which degrades the heat-shock transcription factor $\sigma^{32}$. EMBO J 14, 2551-2560.

Tomoyasu, T., Yuki, T., Morimura, S., Mori, H., Yamanaka, K., Niki, H., Hiraga, S. \& Ogura, T. (1993a). The Escherichia coli FtsH protein is a prokaryotic member of a protein family of putative ATPases involved in membrane functions, cell cycle control, and gene expression. J Bacteriol 175, 1344-1351.

Tomoyasu, T., Yamanaka, K., Murata, K., Suzaki, T., Bouloc, P., Kato, A., Niki, H., Hiraga, S. \& Ogura, T. (1993b). Topology and subcellular location of FtsH protein in Escherichia coli. J Bacteriol 175, 1352-1357.

Yanouri, A., Daniel, R. A., Errington, J. \& Buchanan, C. E. (1993). Cloning and sequencing of the cell division gene $p b p B$, which encodes penicillin-binding protein $2 \mathrm{~B}$ in Bacillus subtilis. $J$ Bacteriol 175, 7604-7616.

Received 11 June 1996; revised 24 September 1996; accepted 14 October 1996. 